\title{
METODOLOGIAS ATIVAS: EFEITOS DE VERDADE ACERCA DA INOVAÇÃO NO ENSINO DENTRO DA RACIONALIDADE NEOLIBERAL
}

\author{
ACTIVE METHODOLOGIES: TRUTHS ABOUT INNOVATION IN TEACHING IN \\ NEOLIBERAL RATIONALITY
}

\author{
Rafaela Esteves Godinho Leal \\ Mestre em Educação, Universidade Federal de Minas Gerais - UFMG \\ Belo Horizonte, Minas Gerais - Brasil. \\ rafaelegodinho@yahoo.com.br \\ Shirlei Rezende Sales \\ Doutora em Educação, Universidade Federal de Minas Gerais - UFMG \\ Belo Horizonte, Minas Gerais - Brasil. \\ shirlei.sales@hotmail.com
}

\begin{abstract}
Resumo: A inovação tornou-se um imperativo na sociedade contemporânea. Nela, à docência universitária é convocada a utilizar metodologias ativas como forma de inovar no ensino. Divulga-se que essas metodologias produzem sujeitos ativos e autônomos. Nesse sentido, neste artigo busca-se compreender os efeitos de verdade acerca das metodologias ativas na produção de estudantes ativas/os. Ele traz parte dos resultados de uma pesquisa, cujo corpus é constituído pelos ditos em circulação no curso de formação de professoras/es universitárias/os, bem como de entrevistas realizadas com participantes dessa formação. Utilizou-se como referencial as ferramentas teóricas e analíticas do filósofo Michel Foucault, a saber: dispositivo, discurso, poder e verdade. Por meio da rede metodológica que articulou elementos da netnografia educacional, de entrevistas narrativas e da análise do discurso de inspiração foucaultiana, desenvolveu-se o argumento de que a docência inovadora está em continuidade com a produção da posição de sujeito discipulus iacto. Conclui-se que as demandas postas à docência universitária inovadora, para utilizar metodologias ativas, atendem à urgência de forjar a posição de sujeito discipulus iacto na racionalidade neoliberal. As demandas pelo uso de metodologias ativas, portanto, governam as condutas discentes e docentes no ensino universitário inovador.
\end{abstract}

Palavras-chave: docência do ensino superior; inovação; metodologias ativas; racionalidade neoliberal.

\begin{abstract}
Innovation has become a must in contemporary society. In it, university teaching is called to use active methodologies as a way to innovate in teaching. It is reported that these methodologies produce active and autonomous subjects. In this sense, this article seeks to understand the effects of truth about the active methodologies in the production of active students. It brings part of the results of a research, whose corpus is constituted by the said in circulation in the course of training of university teachers, as well as of interviews with participants of this formation. The theoretical and analytical tools of the philosopher Michel Foucault were used as reference, namely: device, discourse, power and truth. Through the methodological network that articulated elements of educational netnography, narrative interviews and the analysis of Foucauldian-inspired discourse the argument was developed that innovative teaching is in continuity with the production of the position of subject discipulus iacto. It is concluded that the demands placed on innovative university teaching, to use active methodologies, respond to the urgency of forging the position of disciple subject iacto in neoliberal rationality. The demands for the use of active methodologies, therefore, govern the student and teaching conducts in the innovative university education.
\end{abstract}

Keywords: teaching of higher education; innovation; active methodologies; neo-liberal rationality.

Para citar - (ABNT NBR 6023:2018)

LEAL, Rafaela Esteves Godinho; SALES, Shirlei Rezende. Metodologias ativas: efeitos de verdade acerca da inovação no ensino dentro da racionalidade neoliberal. Eccos - Revista Científica, São Paulo, n. 57, p. 1-19, e10725, abr./jun. 2021. Disponível em: https://doi.org/10.5585/eccos.n57.10725. 


\section{Introdução}

A inovação está na ordem do discurso nos tempos atuais (LEAL, 2017). Demanda-se dos sujeitos que eles "precisam se tornar inovadores, e não somente as empresas e seus laboratórios ou centros de Pesquisa e Desenvolvimento (P\&D)" (OLIVEIRA; FERREIRA; MORAES, 2015, p. 128). Parece haver, de acordo com Ferry (2015), uma tendência das sociedades modernas à inovação, e "não apenas na esfera econômica, mas também em todos os campos da existência humana - a arte, os costumes, os valores, o vestuário, a cultura, a informação, a tecnociência, a escola" (p. 12). Com isso, a inovação tem se tornado um imperativo nos tempos atuais (LEAL, 2017).

No âmbito educacional, presenciamos demandas por inovação no ensino. A pesquisa ${ }^{1}$ que resultou este artigo teve por objetivo central investigar o dispositivo de inovação em atuação no ensino superior na produção de docentes inovadoras/es e estudantes ativas/os na sociedade contemporânea. Para isso, foram analisados os ditos de um curso de formação de professoras/es universitárias/os, por meio de uma rede metodológica que articulou elementos da netnografia educacional, de entrevistas narrativas e da análise do discurso de inspiração foucaultiana ${ }^{2}$.

Observou-se que as/os docentes são incitadas/os, nos ditos analisados, a atuarem como mediadoras/es e/ou facilitadoras/es, utilizarem metodologias ativas e integrarem tecnologias digitais em seus processos de ensino-aprendizagem na constituição de práticas inovadoras no ensino universitário. Esses elementos tornarem-se marcas características da docência inovadora, conduzindo a conduta dos sujeitos (docentes e discentes) na educação superior.

Nessa condução da ação educativa, demanda-se nos discursos analisados, constituintes do dispositivo de inovação, que as/os professoras/es utilizem, por exemplo, metodologias ativas. Elas estão na ordem do discurso de inovação no ensino universitário e têm como alvo fabricar estudantes ativas/os, autônomas/os, empreendedores e competitivas/os a fim de atender ao funcionamento da "sociedade da inovação" (LEAL, 2017) inscrita na racionalidade neoliberal. Parece haver, portanto, uma continuidade discursiva em utilizar metodologias ativas e produzir sujeitos ativos.

É divulgado, nos discursos analisados, que se está inovando ao formar estudantes ativas/os, autônomas/os, empreendedores e competitivas/os com o uso de metodologias ativas. Nesse sentido, este artigo tem como objetivo central compreender os efeitos de verdade acerca

\footnotetext{
Investigamos essa produção em uma pesquisa a qual será identificada após aprovação do trabalho pela Revista, com o intuito de garantir o sigilo da autoria e não comprometer o processo de avaliação pelos pares.

Essa rede será melhor descrita na próxima seção do artigo.
} 
das metodologias ativas na produção de estudantes ativas/os em prol da inovação no ensino. Essas verdades divulgadas atendem a que tipo de urgência da sociedade contemporânea e da racionalidade governamental vigente?

Então, para analisar essas demandas discursivas, nós apoiamos nos estudos do filósofo Michel Foucault. Para esse autor, o discurso forma os objetos de que fala (FOUCAULT, 2015a). Logo, é por meio das "nomeações, descrições e concepções que construímos conhecimentos e podemos agir sobre nós mesmos e sobre os outros" (TRAVERSINI; BALEM; COSTA, 2007, p. 4). Dessa maneira, os discursos se constituem em um dos elementos do dispositivo de inovação que atuam na produção de sujeitos inovadores na racionalidade governamental vigente, qual seja: o neoliberalismo.

De acordo com Foucault (2008a, p. 181), o neoliberalismo constitui-se "numa arte de governar os princípios formais de uma economia de mercado". O autor salienta que se trata de uma forma de governo que obedece às leis econômicas. Para ele, a arte de governar encontra seu fundamento a partir do econômico e a tarefa política é basicamente criar condições para que a economia se desenvolva. Para isso, o Estado tem toda a sua ação dirigida no sentido de assegurar a concorrência. A atuação do Estado na racionalidade neoliberal objetiva realizar interferências mínimas em relação ao econômico, mas agir ao máximo no que se refere à garantia do mercado concorrencial. Enfim, nessa racionalidade, a atividade do Estado visa fornecer condições de possibilidade para a concorrência.

Diante dessa conclamada concorrência é preciso inovar para vencer. Coloca-se em jogo, portanto, a conduta dos sujeitos inscritos nessa forma de governo. Elas/es são incitadas/os pelo dispositivo de inovação a se tornarem inovadoras/es, a fim de alimentar a lógica da concorrência, constituindo, assim, a "sociedade da inovação".

Nesse tipo de sociedade exige-se a produção da posição estudantes ativas/os, que é caracterizada pela autonomia, pelo protagonismo e pela iniciativa discente, características forjadas nessa sociedade, cujos efeitos acabam por sustentá-la em um movimento também contínuo. Veiga-Neto e Traversini (2009) afirmam que as posições de sujeito são subordinadas ao todo social. Em outras palavras, elas estão afinadas com a racionalidade governamental vigente e com ela coadunam.

Nesse sentido, a articulação entre a "sociedade da inovação" e a produção da/o discente ativa/o, autônoma/o, pro-ativa/o, criativa/o e inovador/a - que nomeamos como discipulus iacto - ${ }^{3}$ se dá por meio da docência universitária inovadora. Esta é demandada a produzir a/o

\footnotetext{
${ }^{3}$ Nomeamos em latim as posições de sujeito observadas, a fim de singularizá-las.
} 
estudante autônoma/o por meio do emprego das metodologias ativas nos processos de ensinoaprendizagem. O dito de que essas metodologias possibilitam a produção de sujeitos autônomos tem status de verdade nos discursos constituintes do dispositivo de inovação na educação superior, engendrando uma continuidade discursiva entre docência inovadora, metodologias ativas e discipulus iacto.

Argumentamos, neste artigo, que a docência inovadora está em continuidade com a produção da posição de sujeito discipulus iacto. As demandas postas à docência universitária inovadora, para utilizar metodologias ativas, atendem à urgência de forjar a posição de sujeito discipulus iacto para o funcionamento da racionalidade neoliberal.

Na perspectiva foucaultiana, sujeito é tido como construção no e pelo discurso e também pela "instabilidade e provisoriedade das múltiplas posições em que são colocados pelos múltiplos e cambiantes discursos em que são constituídos" (SILVA, 2011, p. 251). A posição de sujeito discipulus iacto é marcada pela autonomia, proatividade e competitividade, características necessárias ao funcionamento da racionalidade neoliberal na garantia da concorrência.

Para esse desenvolvimento, este artigo está organizado em seções. Na primeira seção, apresentamos a rede metodológica da investigação e, logo após, a rede teórica. Em seguida, apresentamos as análises elaboradas às demandas postas às/aos docentes universitárias/os na utilização de metodologias ativas, como forma de inovar nos processos de ensino e aprendizagem na educação superior. Por fim, apresentamos as conclusões de nossas análises.

\section{Rede metodológica: netnografia educacional, entrevistas narrativas e análise do discurso}

Tomamos a perspectiva das teorias pós-críticas, a partir da vertente pós-estruturalista, para desenvolver os caminhos metodológicos da pesquisa que originou o presente artigo. Escolhemos a netnografia educacional como um dos caminhos metodológicos, visto que iríamos realizar a investigação em um curso de formação de professoras/es cuja carga horária é prevalentemente on-line no Ambiente Virtual de Aprendizagem (AVA). De acordo com Veiga (2010, p.14), muitos titulados dos programas de mestrado e doutorado atuam na docência universitária sem ter tido, de maneira geral, uma formação específica para exercer essa atividade. É recente a oferta, no Brasil, de cursos de formação em docência do ensino superior. Pimenta e Anastasiou (2010, p.88) consideram mais pertinente nomear esse tipo de formação como "desenvolvimento profissional dos professores do ensino superior", por considerar que “envolve ações e programas quer de formação inicial quer de formação em serviço". Para as 
autoras, o desenvolvimento profissional de professores tem como objetivo valorizar a capacidade de decisão dos docentes universitários. Elas apontam que o docente, "ao confrontar suas ações cotidianas com as produções teóricas, impõe-se a revisão de suas práticas e das teorias que as informam, pesquisando a prática e produzindo novos conhecimentos para a teoria e a prática de ensino (PIMENTA; ANASTASIOU, 2010, p.89).

Os ditos em circulação pesquisados foram do "Percurso Formativo em docência do ensino superior" que é ofertado por uma universidade pública. Realizamos a observação no ambiente on-line da sétima oferta do curso entre os meses de março a junho de 2016, com 140 inscritos. O Percurso está organizado em dez unidades temáticas, em que os inscritos participam de atividades on-line como oficinas, fóruns e construção de textos coletivos. Por fim, eles apresentam um plano ou registro de ação pedagógica, mostrando as inovações desenvolvidas ou o que pretendem inovar em suas aulas. Tem-se o eixo geral, que é comum a todas/os as/os inscritas/os, e os eixos específicos, nos quais os/as participantes escolhem os temas mediante seus interesses formativos.

Observar um ambiente virtual em que professoras/es dialogam sobre suas práticas de ensino, trocam experiências sobre a docência e elaboram planos de ação, que visam inovar no ensino de graduação, proporcionou identificar verdades divulgadas sobre inovação na docência universitária. No entanto, entendemos que somente essa imersão não seria suficiente para responder ao problema de pesquisa: "como a/o docente inovador/a é produzida/o no ensino superior?". Por essa razão, criamos uma rede metodológica. Em outras palavras, articulamos procedimentos metodológicos a fim de responder ao problema de pesquisa proposto na investigação. Assim, aliamos a netnografia educacional à entrevista narrativa e à análise do discurso de inspiração foucaultiana na construção dessa rede metodológica.

Para Amaral, Natal \& Viana (2008), a netnografia consiste na transposição da etnografia para o estudo de práticas comunicacionais mediadas por computador. Para Kozinets (2014, p.62), a netnografia "é pesquisa observacional participante baseada em trabalho de campo online". Kozinets (2014, p.62) também argumenta que a netnografia "usa comunicações mediadas por computador como fonte de dados para chegar à compreensão etnográfica de um fenômeno cultural ou comunal". Assim, a netnografia "amplia o leque epistemológico dos estudos em comunicação e cibercultura" (AMARAL, NATAL\& VIANA, 2008, p. 35). Utilizamos a netnografia para a realização da observação e participação nas atividades on-line do curso. A carga horária dessa formação foi de sessenta horas, sendo dez horas presenciais e cinquenta horas on-line. Um tempo significativo da pesquisa de campo foi dispendido no 
ambiente on-line do Percurso. Na criação da rede metodológica, articulamos a abordagem netnográfica à entrevista narrativa.

Esta "permite ao/à narrador/a a elaboração de imagens de si, da/o outra/o e do mundo e a atribuição de significados às suas experiências, constituindo-se como forma discursiva privilegiada para a compreensão das interpretações dos sujeitos sobre si mesmos, numa possível invenção de si” (TEIXEIRA, 2006, s/p). Esse tipo de entrevista busca compreender a constituição da subjetividade e as transformações que acompanham os sujeitos. Tendo em vista que a entrevista é uma situação discursiva, nela estão implicadas relações de poder, emoções, sentimentos (TEIXEIRA, 2006, s/p).

Isso em vista, realizamos as entrevistas narrativas com cinco professoras/es que participaram do Percurso Formativo e avaliaram que o curso forneceu elementos para inovarem em suas práticas de ensino. Selecionamos as/os docentes por meio da análise da atividade final do Percurso, em que elas/es entregaram o registro e/ou plano de ação pedagógico inovador. Entrevistamos, portanto, 05 professoras/es, tendo o plano de ação como critério da seleção para participarem da etapa das entrevistas narrativas. Todas/os as/os entrevistadas/os são doutoras/es e têm entre um a cinco anos de experiência na docência. Nesse sentido, ao realizar e analisar as entrevistas não buscamos "verdades" a serem reveladas, mas procuramos entendê-las como “embebidas nos discursos de seu tempo, da situação vivida, das verdades instituídas para os grupos sociais" (SILVEIRA, 2007, p.129). Para isso, tornou-se importante analisá-las buscando por regularidades e irregularidades discursivas, compondo, assim, a rede metodológica que articulou também elementos da análise do discurso de inspiração foucaultiana.

Esse tipo de análise discursiva tem como pressuposto o entendimento de que o discurso consiste em uma prática produtiva que fabrica saberes, verdades e subjetividades (FOUCAULT, 2015b). Para Foucault (2015b), o discurso veicula e produz poder. Sendo assim, os ditos sobre inovação mapeados nas entrevistas e no ambiente virtual do curso foram analisados buscando-se entender a constituição da docência universitária inovadora. Por isso, analisamos o discurso "tal qual ele é” (FOUCAULT, 2010, p. 253). Nessa perspectiva, não se procura encontrar, "por trás do discurso, alguma coisa que seria o poder e sua fonte" (FOUCAULT, 2010, p. 253). Mas examinamos "as diferentes maneiras pelas quais o discurso desempenha um papel no interior de um sistema estratégico em que o poder está implicado, e para o qual o poder funciona" (FOUCAULT, 2010, p. 253).

A fim de acompanhar o curso, constituímos o diário de campo em que realizávamos as descrições e as reflexões das atividades presenciais e on-line dos Percursos. Além disso, produzimos os documentos eletrônicos com os posts de cada atividade on-line: oficinas, fóruns 
e planos de ação. Após tal organização, mapeamos os posts por suas recorrências temáticas e as separamos em arquivos eletrônicos.

O acompanhamento da oferta da formação e as entrevistas foram realizadas no início do primeiro semestre de 2016. Elas auxiliaram a identificar verdades divulgadas sobre inovação nesse nível de ensino e as demandas postas aos professores universitários. Após a constituição dessas informações, a partir de agosto de 2016, organizamo-las por suas regularidades e irregularidades discursivas para iniciar o procedimento de análise de discurso de inspiração foucaultiana. Nesse tipo de análise não interessa buscar se o que estava sendo divulgado é falso ou verdadeiro; ao contrário, o que importa é identificar e analisar os "efeitos de verdade" que produz.

Esta pesquisa se sustentou em princípios éticos, foi submetida e autorizada pelo Comitê de Ética em Pesquisa - CAAE 50259015.3.0000.5149 com comprovante 106746/2015. Ela apresentou o mínimo de riscos aos indivíduos em suas participações, seja por meio das entrevistas seja por meio da observação do ambiente virtual de aprendizagem. Preservamos o anonimato das/os participantes, utilizando nomes de estrelas (Kajam, Chertan, Jih, Caph, Polaris, Ancha e Mira) para referi-las/os, os quais são mencionados nos trechos extraídos das entrevistas e dos ditos em circulação no curso. Em articulação com essa rede metodológica, traçamos uma rede teórica da investigação, que apresentamos na seção seguinte.

\section{Rede teórica da investigação: discurso, verdade, poder, inovação e neoliberalismo}

O fio da rede que entrelaçou os conceitos desenvolvidos na investigação que subsidia este artigo foi o discurso. Entendemos discurso, na concepção foucaultiana, como "práticas que formam sistematicamente os objetos de que falam" (FOUCAULT, 2008b, p. 55). É nessa perspectiva que analisamos o discurso de inovação na docência universitária, como um dos elementos do dispositivo de inovação que atua na produção de sujeitos. Partimos também do entendimento de que, “o sujeito é produzido 'como efeito' do discurso e no discurso, no interior de formações discursivas específicas" (HALL, 2014, p.120). Tendo em vista que os sujeitos são vistos como constituídos no e pelo discurso, pudemos perceber, na pesquisa que subsidia este artigo, que as/os professoras/es são convocadas/os a ocuparem a posição de sujeito docentis innovatus. Ou seja, há demandas discursivas para que as/os professoras/es se tornem inovadoras/es no ensino a fim de atender demandas da racionalidade neoliberal.

Foucault analisa a inovação na inscrição da racionalidade neoliberal, no livro Nascimento da biopolítica (2008a). O autor discute inovação inscrita no campo econômico e 
político, entendendo-a como a descoberta de novas técnicas, de novas fontes, de novas formas de produtividade, de novos mercados e de novas fontes de mão de obra (FOUCAULT, 2008a). Parece-nos que Foucault empreende sua análise sobre inovação relacionando-a ao "novo". Esse pode ser da ordem das técnicas, da produção e do mercado. O autor, em a Ordem do discurso (FOUCAULT, 2013), afirma que o novo está no retorno das coisas já ditas, e não no que é dito propriamente. Com base no entendimento foucaultiano sobre o novo, tomamos a noção de inovação tendo em vista a ideia de composição entre experiências, conhecimentos, saberes coisas já ditas - que são ressignificadas pelos sujeitos nos contextos sociais, econômicos, políticos e culturais, fazendo emergir elementos diferentes dos já existentes. (LEAL, 2017). Assim, para Foucault (2008a, p.318):

se inovação existe, isto é, se se encontram coisas novas, se se descobrem novas formas
de produtividade, se se fazem invenções de tipo tecnológica, tudo isso nada mais é
que a renda de um certo capital, o capital humano, isto é, o conjunto de investimentos
que foram feitos no nível do próprio homem.

Tais investimentos constituem-se de habilidades, conhecimentos, atitudes e competências que os sujeitos adquirem e que ganham valor econômico na racionalidade neoliberal. Nesse sentido, é possível pensar que esse conjunto de investimentos produz certo tipo de sujeito, que é o sujeito inovador. Tal sujeito é caracterizado, neste artigo, pelo investimento que faz sobre si mesmo, transformando conhecimento, descobertas de coisas e processos novos em renda ou capital. Dessa maneira, esse sujeito torna-se empresário de si mesmo, "sendo ele próprio seu capital, sendo para si mesmo seu produtor, sendo para si mesmo a fonte de [sua] renda" (FOUCAULT, 2008a, p. 311). Trata-se, portanto, de um sujeito que é convocado a fazer investimentos em si a fim de obter a sua renda, a partir da produção de coisas ou processos novos.

A produção da inovação na docência universitária está inscrita nos discursos em circulação no ensino superior articulados às relações de poder. Essa é uma noção de extrema relevância nesta trama conceitual. De acordo com a perspectiva foucaultiana, o poder se constitui em "feixes de relações de poder, de relações de força" (FONSECA 1995, p. 30). Essa noção de poder como relação exprime o seu caráter difuso e ramificado. O poder não é fixo, não possui centro, “o poder está em toda parte; não porque englobe tudo e sim porque provém de todos os lugares" (FOUCAULT, 1988, p. 88). Por isso, as relações de poder são entendidas como micropoderes (FONSECA, 1995, p. 33). A partir dessa perspectiva, analisamos a produção do discipulus iacto como uma posição de sujeito que se constitui por relações de 
poder. Em outras palavras, as relações de poder estão em toda parte conduzindo as ações de umas/uns sobre outras/os na sociedade.

Diante disso, para Foucault, o poder é constituído por relações complexas que produzem verdades e subjetividades. Essas relações "agem em muitos sentidos, podendo ser consideradas multidirecionais, uma vez que operam de baixo para cima e de cima para baixo" (FONSECA, 1995, p. 31). O poder, nessa perspectiva, não significa apenas "conjunto de instituições e aparelhos garantidores da sujeição dos cidadãos em um Estado determinado" (FOUCAULT, 1988, p. 88). Dessa maneira, para Foucault (2015b, p. 102), “as relações de poder não estão em posição de superestrutura, com um simples papel de proibição ou de recondução; possuem, lá onde atuam, um papel diretamente produtor". Para ele, o poder não se exerce somente pelo Estado ou por dominadoras/es em oposição às/aos dominadas/os,

deve-se, ao contrário, supor que as correlações de forças múltiplas que se formam e atuam nos aparelhos de produção, nas famílias, nos grupos restritos e nas instituições servem de suporte a amplos efeitos de clivagem que atravessam o conjunto do corpo social" (FOUCAULT, 2015b, p. 102).

Nesse sentido, buscamos estabelecer o elo entre as relações de poder com a produção da posição de sujeito discipulus iacto nos discursos analisados. Entendendo que nem a "casta que governa, nem os grupos que controlam os aparelhos do Estado, nem aqueles que tomam as decisões econômicas mais importantes" (FOUCAULT, 2015b, p. 103) são os únicos responsáveis pela produção de tal posição. Ela é fabricada por meio da racionalidade do poder no nível de verdades que atuam na produção da docência inovadora.

As verdades produzidas estão estreitamente relacionadas ao poder. Sendo assim, "a verdade não existe fora do poder ou sem o poder" (FOUCAULT, 2014, p. 52). Por verdade, Foucault (2014, p. 54) entende "um conjunto de procedimentos regulados para produção, a lei, a repartição, a circulação e o funcionamento dos enunciados". Verdade, portanto, não se trata de coisas verdadeiras que se deve aceitar (FOUCAULT, 2014, p. 53), mas é preciso entendê-la como "conjunto de regras segundo as quais se distingue o verdadeiro do falso e se atribui ao verdadeiro efeitos específicos de poder" (p. 53). Essa ligação entre poder e verdade constitui os "regimes de verdade". Na perspectiva foucaultiana, não existe uma verdade única. Existem discursos que são posicionados como verdadeiros e adquirem status de verdade em determinada sociedade. Assim, ele busca mostrar as estratégias e os procedimentos da produção do verdadeiro. De acordo com Foucault (2014), cada sociedade tem sua "política geral" de verdade, que funciona por meio de mecanismos, os quais sancionam determinados discursos em detrimento a outros, bem como por técnicas e procedimentos que são valorizados para 
obtenção da verdade. Com base na articulação entre essa rede teórica aqui descrita e a rede metodológica apresentada na seção anterior, elaboramos a análise das informações produzidas. A seguir, discutimos, portanto, a produção do status de verdade das metodologias ativas no discurso de inovação no ensino, atuando na produção da/o discente autônoma/o, pró-ativa/o, empreendedora/or e competitiva/o.

\section{Análise das informações produzidas acerca das metodologias ativas: inovação no ensino superior inscrita na racionalidade neoliberal}

A atuação das/os professoras/es como mediadoras/es e facilitadoras/es é uma marca característica da docência inovadora, conduzindo o que pode ser dito e feito no âmbito do ensino universitário inovador (LEAL, 2017). Nessa condução da ação educativa, demanda-se nos discursos analisados, constituintes do dispositivo de inovação, que as/os professoras/es utilizem, por exemplo, metodologias ativas. Elas estão na ordem do discurso de inovação no ensino universitário e têm como alvo fabricar estudantes ativas/os. Pode-se observar no trecho da entrevista com a professora Kajam a relação entre inovação e estudante ativo.

\footnotetext{
Primeiro momento que eu considero que está tendo inovação é quando o aluno se torna mais ativo. Acho que a gente já consegue uma inovação quando ele participa mais, né, quando a turma participa mais, quando ela se empodera mesmo. Ela começa a aplicar né, aquilo que tá sendo, às vezes, colocado pelo professor, na sua prática também discente, como por exemplo, às vezes você dá uma aula discursiva, uma roda de discussão, e aí você propõe um seminário, aí no seminário você vê que também eles estão compondo rodas de discussões, dinâmicas, e tal. Aí você fala, mexeu de alguma forma, porque eles também saíram do convencional, de ficar só com slide e tal. Eu considero que está tendo inovação, eu acho que a inovação acontece quando a gente percebe esse aluno mais ativo no processo, e aí a partir desse momento a gente consegue ousar mais. (Trecho da entrevista com a professora Kajam).
}

Para Kajam, a inovação no ensino universitário acontece quando a/o estudante se torna mais ativo no seu processo de aprendizagem. Ela entende que a inovação está relacionada à participação das/os discentes nas atividades propostas que saem do "convencional", consideradas inovadoras. É possível notar que tal discurso compõe o dispositivo de inovação e se constitui em contraposição ao que é considerado convencional ou tradicional de ensinar "só com slide e tal". Alguns exemplos de atividades que a docente menciona como inovadoras são rodas de discussão, seminários e dinâmicas. Para ela, essas atividades favorecem a participação da/o estudante. Em outras palavras, a/o professora/or inovadora/or, ao utilizá-las em suas práticas de ensino, possibilita maior participação das/os estudantes, estimulando a formação de um/a estudante ativa/o e participativa/o. Kajam afirma que, a partir do momento em que as/os discentes se tornam ativas/os, as/os professoras/es conseguem "ousar mais". Pode-se perceber, 
portanto, uma relação de continuidade discursiva entre a/o discente ativa/o, as metodologias ativas e a/o docente inovadora/or.

Nesse sentido, os discursos, integrantes do dispositivo de inovação, convocam as/os professoras/os universitárias/os a formarem estudantes ativas/os por meio da utilização de metodologias ativas e se inscrevem na "sociedade da inovação" como "economia política" da verdade, que está submetida à incitação econômica e política, isto é, a demandas próprias da racionalidade neoliberal. Essa racionalidade requer sujeitos ativos, criativos e inovadores, portanto, ela tem "necessidade de verdade tanto para a produção econômica, quanto para o poder político" (FOUCAULT, 2015b, p. 52). Kuenzer (2012, p. 17), ao analisar o que se altera no cotidiano da sala de aula universitária com transformações do mundo do trabalho, afirma que as complexidades dos instrumentos de produção, o mercado em permanente movimento e a microeletrônica exigem "criação de soluções inovadoras, rapidez de resposta, comunicação clara e precisa, interpretação e uso de diferentes formas de linguagens, capacidade para trabalhar em grupo [...], enfrentar os desafios de mudanças permanentes". Além de formar sujeitos criativos e ativos, essa racionalidade requer sujeitos capazes de aprenderem constantemente e que saibam trabalhar em equipe, contemplando as necessidades da "sociedade da inovação" e do mercado. Isso pode ser visto no texto coletivo desenvolvido pelas/os professoras/es participantes dos Percursos quando falam da necessidade de produzir esse tipo de sujeito para o mercado.

\footnotetext{
Faz-se necessário um link direto e imediato com o mercado de trabalho. A teoria deve estar preparada para dar suporte e fundamentação para a prática profissional. O mercado de trabalho precisa de pessoas cada vez mais qualificadas, com mais conhecimento e bem informadas. Faz-se necessário despertar e evidenciar os perfis criativos e proativos, que pensem, que discutam, que tenham autonomia. Profissionais que dominem o novo contexto social, as novas tecnologias e possuam competência para resolver questões do dia a dia profissional. (Trecho do texto coletivo desenvolvido no Percurso Formativo pelas/os professoras/es participantes).
}

De acordo com o texto coletivo produzido pelas/os professoras/es participantes do Percurso Formativo, é necessário despertar "perfis criativos e proativos" que também tenham "autonomia" para atender ao "mercado de trabalho". Além disso, de acordo com o texto, é necessário formar "profissionais que dominem o novo contexto social, as novas tecnologias e possuam competências para resolver questões do dia a dia profissional'. É possível perceber nesse trecho a relação entre a demanda por sujeitos ativos, autônomos e competentes na resolução de problemas com as necessidades da "sociedade da inovação”. Esse discurso veicula que essa relação é necessária e deve ser feita de imediato, tendo efeitos de "verdades". É 
possível pensar, dessa maneira, que se está inovando ao formar esses "perfis" de sujeitos para atender às demandas da sociedade.

Assim, para a produção desses “perfis", percebe-se uma incitação, em torno da formação das/os profissionais da atualidade. Ou seja, a formação no ensino superior deve atender à racionalidade neoliberal, cujo dizer é a necessidade de profissionais ativas/os. Nessa direção, para se constituírem como inovadoras/es, as/os professoras/es universitárias/os são convocadas/os a desenvolver atividades que tornem as/os estudantes mais ativas/os no seu processo de aprendizagem. Isso pode ser visto nos planos de ação inovadores que as/os professoras/es apresentam no Percurso Formativo.

[...] incluir mais os alunos na aula, deixá-los num papel mais ativo e não passivo. (Trecho do Plano de ação pedagógica - docente Chertan).

[...] a participação ativa dos alunos no processo de aprendizagem pode gerar um resultado muito melhor. (Trecho do Plano de ação pedagógica - docente Jih e Caph).

Assim, sinto a necessidade de estar operacionalizando da melhor forma possível a troca de conhecimentos com a turma e que os alunos sejam sujeitos ativos neste processo. (Trecho do Plano de ação pedagógica - docente Kajam).

Pode-se notar, a partir desses trechos, que há uma demanda por práticas de ensino que favoreçam a "participação ativa" das/os estudantes. Para Jih e Caph, essa participação pode gerar "um resultado muito melhor". Esses ditos constituem-se em verdades divulgadas que legitimam o uso de metodologias ativas. Afinal, esses mecanismos possibilitam a participação das/os estudantes e, consequentemente, melhores aprendizagens. À/Ao professora/or, por meio de suas características inovadoras, cabe fomentar e gestar a formação desse sujeito ativo. Assim, as marcas constitutivas da posição docentis innovatus atuam na produção do discipulus iacto, em uma continuidade discursiva.

Parece que a docente Ancha considera haver uma continuidade discursiva entre as técnicas dos jogos interativos, a participação discente, o prazer e a aprendizagem ativa.

\footnotetext{
Minha intenção, no próximo semestre, é tornar as aulas bem menos expositivas e mais participativas. A partir dos feedbacks dos colegas, conheci novas técnicas que irei aplicar na disciplina. A inovação metodológica partirá de uma ideia compartilhada pelos colegas do curso: jogos jeopardy, jogos interativos entre os alunos. Minha ideia é dividir a turma em grupos, para que eles se posicionem e defendem, como advogados, cada uma das vertentes teóricas da economia do meio-ambiente. Acredito que irá aguçar o entusiasmo e a emoção nos alunos, fazendo com que a aprendizagem seja prazerosa. E complementarmente, esta também será uma nova forma de avaliação dos alunos. (Trecho do Plano de ação - docente Ancha).
} 
De acordo com Oliveira (2014), a aprendizagem ativa trata-se de um processo que exige a participação constante da/o discente nas propostas educativas. Segundo o autor, nesse tipo de aprendizagem a/o aluna/o é "protagonista do processo de ensino-aprendizagem em que os seguintes aspectos são destacados: o 'fazer' e o 'pensar' sobre todas as atividades que estejam desenvolvendo" (p. 4). Para Valente (2019), na aprendizagem ativa o discente "resolve problemas, desenvolve projetos e, com isto, cria oportunidades para a construção de conhecimento" (p. 1). Ainda de acordo o autor, "diversas estratégias têm sido utilizadas para promover a aprendizagem ativa como a aprendizagem baseada na pesquisa, o uso de jogos ou o Problem Based Learning (PBL)” (p. 1). Filho e Ribeiro (2008), em artigo que versa sobre inovação com uso de PBL ou Aprendizagem Baseada em Problemas (ABP), afirmam que o PBL consiste em "uma metodologia de ensino-aprendizagem surgida na escola de medicina da Universidade McMaster, no Canadá” (p. 2). Ela utiliza, segundo os autores, uma abordagem para "iniciar, enfocar e motivar a aprendizagem de conhecimentos social e profissionalmente relevantes" (p. 3). Assim, no ensino superior, essa metodologia é veiculada nos discursos como inovadora, por se entender que favorece a resolução de problemas. É possível pensar que tais problemas podem se constituir como efeitos da "sociedade da inovação". Para resolvê-los, os sujeitos são incitados a inovar e a fazer diferente, atendendo à lógica concorrencial da racionalidade neoliberal. Esta necessita desse tipo de sujeito, que fabrica coisas e processos novos a fim de produzir renda, tornarem-se empreendedores de si, atuando no funcionamento do mercado. Assim, pode-se compreender que as metodologias ativas formam esse tipo de sujeito inovador para operar nessa racionalidade.

Os jogos são também utilizados pelas/os professoras/es a fim de inovar na docência universitária. Para Arruda (2009), os jogos digitais têm uma dimensão lúdica e trazem modificações nas maneiras de ensinar e aprender. Ademais, eles têm o potencial de engajar as pessoas e motivá-las por meio de desafios a serem conquistados. Para Garbin (2014), a gamificação, especificamente, tem como principal estratégia a "sensação de vitória", ou seja, sentir que ganhou o jogo e seguir para a próxima fase. Essa sensação, quando utilizada na educação para promover a aprendizagem, pode se tornar o elemento motivador do estudante durante sua trajetória acadêmica (GARBIN, 2014). Ainda segundo Garbin (2014), a gamificação pode se desenvolver em qualquer ambiente,

criando um fator lúdico ou competitivo na busca da resolução de problemas chave, ampliando o estímulo positivo para os vencedores. Assim qualquer instituição de ensino superior consegue inserir em sua metodologia de ensino, de alguma forma, a gamificação. (p. 8). 
Algumas estratégias da gamificação podem auxiliar no engajamento das/os estudantes nos seus processos de aprendizagem, como as regras, a meta, a competição e/ou cooperação e o sistema de feedback. A gamificação na educação costuma ser denominada também como Game Based Learning (GBL), ou seja, Aprendizagem Baseada em Games. É possível notar que a gamificação incita a concorrência e a competitividade, mecanismos de funcionamento da racionalidade neoliberal, os quais operam na constituição de sujeitos inovadores. Como se vê, os discursos relacionados à utilização dos jogos e do processo de gamificação na educação se integram ao dispositivo de inovação, engendrando a produção do discipulus iacto, em continuidade com a docência inovadora e a "sociedade da inovação”.

Outra metodologia ativa mencionada nos planos de ação inovadores das/os professoras/es participantes dos Percursos foi o "estudo de caso", também conhecido como "cases" ou "estudo do caso".

\footnotetext{
Aplicação de cases - estudos de caso, para melhor assimilação e contextualização de situações reais com as quais os alunos podem precisar lidar em sua vida profissional. Cases poderiam ser utilizados de maneira muito útil nas aulas. (Trecho do Plano de ação - docente Mira).
}

Repensar a forma como as aulas têm sido ministradas, procurando mesclar aulas expositivas com atividades mais atrativas como grupos de discussão orientada resolução de questões e estudos de caso, permitindo, assim, uma maior participação do estudante no processo de ensino-aprendizagem. (Trecho do Plano de ação - docente Polaris).

A docente Mira afirma em seu plano de ação que pretende aplicar em suas disciplinas o "estudo de caso", a fim de preparar as/os estudantes para uma "melhor assimilação e contextualização de situações reais". Segundo a professora, as/os alunas/os podem precisar lidar com essas situações em sua vida profissional. A docente Polaris propõe em seu plano de ação "atividades mais atrativas" como os grupos de discussão e o "estudo de caso". Essas metodologias de ensino estão relacionadas às demandas da "sociedade da inovação", pois simulam situações que as/os estudantes possivelmente terão na prática profissional. De acordo com Masetto (2010, p. 134), o estudo de caso tem "por objetivo colocar o aluno em contato com uma situação profissional simulada". Essa simulação pode ser composta por vários aspectos considerados reais. Para Berbel (2011, p. 30), no estudo de caso a/o aluna/o é levada/o “à análise de problemas e tomada de decisões". Essa metodologia favorece que as/os discentes entrem em "contato com situações que podem ser encontradas na profissão e habituá-los a analisá-las em seus diferentes ângulos antes de tomar uma decisão” (BERBEL, 2011, p. 31). Trata-se, portanto, de uma metodologia que coaduna com as necessidades da "sociedade da inovação", uma vez que essa sociedade requer sujeitos que saibam resolver problemas de 
maneira diferenciada, criando soluções inovadoras e sabendo lidar com mudanças. Além disso, essas características favorecem a lógica da concorrência e da competitividade necessárias ao funcionamento da lógica neoliberal.

Observa-se, assim, que o discurso que legitima o uso do estudo de caso como metodologia produz verdades ao divulgar que ele prepara a/o profissional para lidar com situações reais do cotidiano de trabalho, possibilitando "melhor assimilação e contextualização", além de se constituir como uma atividade "atrativa", como se pode notar no trecho do plano de ação de Mira e Polaris. Divulga-se, ainda, que o estudo de caso pode possibilitar a constituição de sujeitos autônomos. Em outras palavras, sujeitos que estão preparados para lidar com problemas nas situações de trabalho e que terão condições de resolvêlos com certo grau de independência ou de autonomia. É possível pensar que esse fato pode diminuir o custo operacional da atividade realizada nas situações de trabalho, podendo gerar, ainda, uma responsabilização do sujeito por sua própria preparação para o trabalho. O "estudo de caso", portanto, é mais uma metodologia ativa demandada ao docentis innovatus na fabricação da posição de sujeito discipulus iacto, a fim de atender às urgências da racionalidade neoliberal em se produzir sujeitos ativos, autônomos, participativos e criativos para a lógica do mercado concorrencial na "sociedade da inovação".

Foi possível observar que as metodologias consideradas ativas são validadas por docentes universitárias/os e adquirem estatuto de verdade de inovação pedagógica na docência do ensino superior. Tal validação constitui-se em um efeito da ordem discursiva vigente da “sociedade da inovação”, que, por sua vez, produz as posições docentis innovatus e discipulus iacto. O uso das metodologias ativas, portanto, faz parte de um discurso autorizado sobre inovação na docência universitária, que é articulado ao dispositivo de inovação na fabricação dessas posições de sujeito. É interessante para lógica do mercado, neste contexto político, histórico e social, em que se constitui a "sociedade da inovação", formar sujeitos ativos, empreendedores de si e competitivos para o funcionamento da concorrência incitada pela racionalidade neoliberal, em cuja centralidade está a liberdade de mercado. As metodologias ativas, engendradas nessas relações de poder, são posicionadas como "verdade" na produção da inovação no ensino, porque elas produzem o tipo de sujeito de que o mercado necessita.

Para Conterno e Lopes (2013, p. 518), as metodologias ativas “possuem raízes teóricas fincadas nas pedagogias não diretivas, respaldadas nos ideais de Escola Nova". As "escolas novas", segundo Cambi (1999), foram difundidas predominantemente na Europa Ocidental e nos Estados Unidos e se firmavam em oposição à escola e à pedagogia tradicional, que desvalorizavam os aspectos ativos, produtivos e criativos das crianças. Ainda afirma Cambi 
(1999) que o trabalho desenvolvido pelas "escolas novas" formou o projeto de educação "ativa", que se nutria de uma visão democrática e progressista, inspirada na participação ativa dos sujeitos na vida social e política. De acordo com Cambi (1999, p. 527), “os grandes 'mestres teóricos' do ativismo devem ser reconhecidos em Dewey e Decroly, em Claparède (e sua escola) e Ferrière, além de Maria Montessori”. Para Ferreti, Zibas e Tartuce (2004), o discurso da participação ativa de estudantes no processo de aprendizagem foi difundido no Brasil por diversos teóricas/os da educação nas décadas de 20 e 30 do século XX, influenciadas/os pelo pensamento de Dewey.

Cambi (1999) sintetizou os grandes temas da pedagogia do ativismo: na centralidade da criança ativa no processo educativo; na valorização do "fazer" por meio de atividades manuais, jogos e trabalhos; na motivação por parte da criança em aprender; na centralidade da realidade que circunda os sujeitos; na socialização e no antiautoritarismo. Assim, para Conterno e Lopes (2013, p. 518), "está se forjando um consenso de que as autodeterminadas metodologias inovadoras, respaldadas pelo não diretivismo pedagógico, poderão responder, de forma progressista, aos problemas da formação superior". Em vista disso, circulam, portanto, ditos de que as metodologias ativas resolverão os problemas enfrentados pelo ensino superior ao serem desenvolvidas pela docência inovadora nos cursos de graduação, sobretudo, ao produzirem discentes ativas/os, autônomas/os e protagonistas de suas formações. Tais ditos atendem às demandas da racionalidade vigente, que divulga as metodologias ativas como inovação no ensino superior para produzir o tipo de sujeito de que necessita: o discipulus iacto.

\section{Considerações finais}

Diante do exposto, é possível notar que as/os professoras/es são conduzidas/os a inovar no ensino superior por meio das metodologias ativas nos processos de ensino-aprendizagem, a fim de produzirem sujeitos autônomos e ativos. Tal constatação parece ter "efeitos de verdade" no discurso de inovação no ensino superior. Em outras palavras, divulga-se que para se inovar no ensino é interessante se produzir estudantes ativos. A fabricação desse tipo de sujeito está na ordem discursiva, adquirindo, assim, status de verdade no discurso de inovação. Mas ela atende a que tipo de demanda ou urgência na sociedade contemporânea? A partir da investigação dos ditos em circulação no curso de formação de professores e nas entrevistas realizadas, identificamos a produção de verdades que favorecem a produção de um tipo de sujeito que faz funcionar a "sociedade da inovação", atendendo a demandas da racionalidade neoliberal. Não são interessantes para essa sociedade sujeitos que reproduzem conhecimento, 
mas sim sujeitos ativos que constroem conhecimentos, criam coisas e processos novos, ou seja, sejam criativos, autônomos, ativos e inovadores. Por isso, segundo Kuenzer (2012), "a formação profissional passa a exigir capacidade para lidar com a incerteza, com a novidade e para tomar decisões rápidas em situações inesperadas" (p.18). Ainda, de acordo com a autora, a memorização de procedimentos passa a ser substituída pela capacidade de utilizar conhecimentos para resolver problemas de maneira inovadora e original. Tal incitação estimula o desenvolvimento de competências necessárias aos sujeitos para o funcionamento do mercado, qual seja: a produção do novo para diferenciação na lógica concorrencial. Dessa forma, as demandas postas à docência universitária inovadora estão em continuidade com a urgência em forjar a posição de sujeito discipulus iacto, para atender às dinâmicas da racionalidade neoliberal que obedece às leis econômicas. Essa posição é produzida na articulação entre as metodologias ativas, que governam as condutas das/os discentes e das/os docentes no ensino universitário.

Parece haver, portanto, uma forma de governo da docência universitária. Tal condução de condutas é acionada pelo dispositivo de inovação a fim de responder à urgência em se produzir sujeitos ativos, autônomos, participativos e criativos na "sociedade da inovação". Diante disso, é possível pensar que se esteja produzindo uma inovação regulada no ensino universitário, uma vez que ela conduz determinadas formas de ensinar e aprender, engendrando sujeitos dos quais necessita a racionalidade neoliberal. Tratam-se, portanto, de inovações no ensino que seguem os imperativos inventados pela/na sociedade contemporânea.

\section{Referências}

AMARAL, Adriana; NATAL, Geórgia, VIANA, Luciana. Netnografia como aporte metodológico da pesquisa em comunicação digital. Farmecos/PUC-RS. Porto Alegre, dezembro, nº 20, p.34-40, 2008.

ARRUDA, Eucidio Pimenta. Jogos digitais e aprendizagens: o jogo Age of Empires III desenvolve ideias e raciocínios históricos de jovens jogadores? 2009. 238f. Tese (Doutorado em educação). Faculdade de Educação, Universidade Federal de Minas Gerais, Belo Horizonte, 2009.

BERBEL, Neusi Aparecida Navas. As metodologias ativas e a promoção da autonomia de estudantes. Semina: Ciências Sociais e Humanas, Londrina, v.32, n.1, p.25-40, jan./jun, 2011.

CAMBI, Franco. História da pedagogia. São Paulo: Fundação Editora da UNESP (FEU), 1999.

CONTERNO, Solange de Fátima Reis; LOPES, Roseli Esquerdo. Inovações do século passado: origens dos referenciais pedagógicos na formação profissional em saúde. Trab. Educ. Saúde. Rio de Janeiro, v.11, n.3, p.503-523, set/dez. 2013. 
CUNHA, Marlécio Maknamara da Silva. Currículo, gênero e nordestinidade. O que ensina o forró eletrônico? 2011.151f. Tese (Doutorado em educação). Faculdade de Educação, Universidade Federal de Minas Gerais, Belo Horizonte, 2011.

FERRETTI, Celso João; ZIBAS, Dagmar Maria Leopoldi; TARTUCE, Gisela Lobo Baptista Pereira. Protagonismo juvenil na literatura especializada e na reforma do ensino médio. Cadernos de pesquisa. v.34, n.122, p.411-423, maio/ago. 2004.

FERRY, Luc. A inovação destruidora: Ensaio sobre a lógica das sociedades modernas. Trad. Véra Reis. Rio de Janeiro: Objetiva, 2015.

FILHO, Edmundo Escrivão; RIBEIRO. Luis Roberto de Camargo. Inovando no ensino de administração: uma experiência com a aprendizagem baseada em problemas (PBL). Cadernos EBAPE.BR. Número Especial, ago. 2008.

FONSECA, Marcos Alves. A preocupação com o sujeito e o poder. In: FONSECA,. Marcos Alves. Michel Foucault e a constituição do sujeito. São Paulo: Educ, 1995. p. 21 -37.

FOUCAULT, Michel. História da sexualidade I. a vontade de saber. 16. ed. Rio de Janeiro: Edições Graal, 1988.

FOUCAULT, Michel . Nascimento da Biopolítica: curso dado no Collége de France (19781979). São Paulo: Martins Fontes, 2008a.

FOUCAULT, Michel. Arqueologia do saber. 7. ed. Rio de Janeiro: Forense-Universitária, 2008b.

FOUCAULT, Michel. Estratégia, poder-saber. 2.ed. Rio de Janeiro: Forense-Universitária, 2010. (Coleção ditos \& escritos; 4).

FOUCAULT, Michel . A ordem do discurso. 23. ed. São Paulo: Edições Loyola, 2013.

FOUCAULT, Michel . Microfísica do poder. 28. ed. Rio de Janeiro: Paz e Terra, 2014.

FOUCAULT, Michel. Arqueologia do saber. 8. ed. Rio de Janeiro: Forense - Universitária, 2015a.

FOUCAULT, Michel. História da sexualidade 1: a vontade de saber. 3. ed. São Paulo: Paz e Terra, 2015b.

GARBIN, Ramon Figueira. Gamificação na docência do ensino superior. 2014. 39f. Trabalho de Conclusão de Curso. Instituto a vez do mestre. Universidade Cândido Mendes, 2014.

HALL, Stuart. Quem precisa de identidade? In: SILVA, T. T. (Org). Identidade e diferença: a perspectiva dos estudos culturais, 15. ed. Petrópolis: Vozes, 2014.

KUENZER, Acacia Zeneida. O que muda no cotidiano da sala de aula universitária com as mudanças no mundo do trabalho. In: CASTANHO, Sérgio; CASTANHO, Maria Eugênia. Temas e textos em metodologias do ensino superior. 7. ed. Campinas, SP: Papirus, 2012. 
KOZINETS, Robert V. Netnografia: realizando pesquisa etnográfica online. Porto Alegre: Penso, 2014.

LEAL, Rafaela Esteves Godinho. Dispositivo de inovação no ensino superior: a produção do docentis innovatus e discipulus iacto. 2017.170f. Dissertação (Mestrado em educação). Faculdade de Educação, Universidade Federal de Minas Gerais, Belo Horizonte, 2017.

LEAL, Rafaela Esteves Godinho; SALES, Shirlei Rezende. Dispositivo de inovação: produção do estudante ativa/o no ensino superior. Revista Diálogo Educacional, v. 19, p. 173-194, 2019.

MASETTO, Marcos Tarciso (org). O professor na hora da verdade: a prática docente no ensino superior. São Paulo: Avercamp, 2010.

OLIVEIRA, João Ferreira; FERREIRA, Adriano de Melo; MORAES, Karine Nunes. A política e a cultura de inovação na educação superior. In: Educação Superior e produção do conhecimento. Campinas: Mercado das Letras, 2015.

OLIVEIRA, Wenderson Alves de. Práticas instrucionais de aprendizagem ativa e Física para o ensino médio. 2014.62f. Dissertação (Mestrado em Física). Instituto de Física, Universidade Federal de Mato Grosso, Cuiabá, 2014.

PIMENTA, Selma Garrido; ANASTASIOU, Léa das Graças Camargos. Docência no ensino superior. São Paulo: Cortez, 2010.

SILVA, Tomaz Tadeu. O sujeito da educação: estudos foucaultianos. Petrópolis. Vozes, 2011.

SILVEIRA, Rosa Maria Hessel. A entrevista na pesquisa em educação - uma arena de significados. In: COSTA, Marisa Vorraber (Org.). Caminhos investigativos II: outros modos de pensar e fazer pesquisa em educação. 2.ed. Rio de Janeiro: Lamparina editora, 2007.

TEIXEIRA, Inês A. de Castro e PÁDUA, Karla Cunha. Virtualidades e alcance das entrevistas narrativas. In: Congresso Internacional sobre pesquisa (auto) biográfica, II, Anais. Salvador: [s.n], 2006. CD-ROM.

TRAVERSINI, Clarice Salete. BALEM, Nair; COSTA, Zuleika Que discursos pedagógicos escolares são validados por professores ao tratar de metodologias de ensino? In: Congresso internacional de educação: pedagogias (entre) lugares e saberes, 5, 20 a 22 de agosto de 2007. Anais. São Leopoldo: Unisinos, 2007.

VALENTE, José Armando. Aprendizagem ativa no ensino superior: a proposta da sala de aula invertida. Disponível em: https://www.pucsp.br/sites/default/files/img/aci/278_agurdar_proec_textopara280814.pdf. Acesso em 19 de junho de 2019.

VEIGA, Ilma Passos Alencastro. (Org). Docentes para educação superior: processos formativos. Campinas: Papirus, 2010.

VEIGA-NETO, Alfredo; TRAVERSINI, Clarice Salete. Por que Governamentalidade e Educação?. Educação e Realidade, v. 34, p. 13-19, 2009. 